sua eficaz exploração e abordagem. Neste trabalho apresentamos um caso clínico, nunca previamente reportado, de um tratamento endodôntico de um segundo molar superior (2. ${ }^{\circ} \mathrm{MS}$ ) definitivo com 6 canais radiculares em que 4 dos mesmos se encontravam na raiz mesio-vestibular (MV): MV1,MV2, MV3 e MV4. Descrição do caso clínico: Paciente do género feminino recorreu a uma consulta com queixas de dor constante. Ao exame clínico e radiográfico o dente 17 apresentava cárie disto-vestibular (DV) e restauração oclusal em amálgama. Ausência de dor à palpação ou mobilidade. Resposta dolorosa à percussão vertical e ausência de resposta ao teste de sensibilidade ao frio. Foi diagnosticada necrose pulpar e periodontite apical sintomática. Foi proposto tratamento endodôntico. Após anestesia, isolamento e acesso sob ampliação com microscópio óptico foi efetuado um refinamento com ponta de ultrassom e identificou-se um extenso sulco de desenvolvimento entre o canal MV e o canal palatino (P), que continha 3 canais adicionais (MV2, MV3 e MV4). Foi realizada a permeabilização, determinação do comprimento radiográfico e a preparação canalar, com o sistema de limas rotatórias Endogal, sob constante irrigação com hipoclorito de sódio 5,25\%. Numa segunda consulta foi realizado o protocolo de irrigação final e a obturação canalar com gutta-percha e cimento. O dente foi definitivamente restaurado com resina composta com recobrimento cuspídeo. Aos cinco meses a paciente encontra-se sem sintomas e radiograficamente sem alterações. Discussão e conclusões: Segundo um estudo prévio, no 2 ' $^{\circ} \mathrm{MS}$ a raiz MV apresenta em $43.8 \%$ das vezes 2 canais radiculares. Uma meta-análise recente conclui que a prevalência do canal MV3 em $2 .^{\circ} \mathrm{MS}$ é de $0,3 \%$. Os casos publicados de MV4 em $1 .{ }^{\circ} \mathrm{MS}$ são raros, e não se encontra na literatura nenhum caso alguma vez descrito de MV4 em 2. ${ }^{\circ} \mathrm{MS}$. No caso aqui apresentado verificou-se a existência de 4 canais radiculares na raiz MV, de configuração tipo XXI (4-1) tendo as raízes P e a DV apenas um canal radicular cada. Casos clínicos de 2 . $^{\circ} \mathrm{MS}$ com esta complexidade anatómica são raros. A utilização de microscópio óptico foi essencial para a deteção e abordagem de todos os canais radiculares. O uso concomitante de pontas US permitiu expor todo o sulco de desenvolvimento radicular e respetivos canais de uma maneira conservadora.

http://doi.org/10.24873/j.rpemd.2020.12.758

\#036 Síndrome de dente fissurado: caso clínico tratado recorrendo a banda ortodôntica

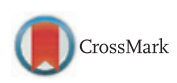

Junedakthar Shaikh, Abayomi Omokeji Baruwa, Mariana Domingos Pires*, Jorge N.R. Martins, António Ginjeira

Dept. de Endodontia - Faculdade de Medicina Dentária Universidade de Lisboa

Introdução: O Síndrome de dente fissurado (SDF) pode ser definido como um plano de fratura de profundidade desconhecida, que é originada a partir da coroa, passa através da estrutura dentária e estende-se até sub-gengival, e pode progredir podendo conectar o espaço pulpar e/ou ligamento periodontal. O objetivo deste trabalho é apresentar o relato de um caso clínico de um dente fissurado tra- tado recorrendo a uma banda ortodôntica. Descrição do caso clínico: Um paciente foi referenciado para Endodontia com queixas de dores contínuas que aumentavam à mastigação. O paciente referiu um episódio de dor intensa. Apresentava o dente $47 \mathrm{com}$ resposta à percussão. A visualização da face distal da coroa mostrou uma linha de fissura. O teste ao frio evidenciou resposta compatível com polpa necrosada. O exame radiográfico mostrou uma aparente estrutura intacta com radiolucidez lateral e apical em ambas as raízes mesial e distal. Foi realizado um diagnóstico de dente fissurado com necrose pulpar e periodontite apical sintomática. Foi planeado o tratamento endodôntico e explicado ao paciente o prognóstico reservado. O bloqueio do nervo alveolar inferior foi administrado. Uma banda ortodôntica foi colocada no molar para estabilizar as estruturas da coroa. O procedimento endodôntico foi realizado sob isolamento absoluto e seguindo as guidelines da European Society of Endodontology. Nenhuma linha de fratura foi detetada envolvendo o chão da câmara pulpar. O tratamento foi completado em 2 consultas. Na segunda visita não apresentava sintomas. Depois de um período de seis meses permanece livre de sintomas. Discussão e conclusões: A incidência de fissuras é considerável em molares inferiores, devido à sua proximidade com a articulação temporomandibular. As opções de tratamento para a síndrome dente fissurado pode envolver, ou não, o tratamento endodôntico (TE), que deve ser complementado com recobrimento cuspídeo em resina, overlay ou coroa completa. A opção de extração não pode ser desconsiderada. A taxa de sobrevivência com TE é de cerca de $85-90 \%$ por um período de 2 anos. A existência de sondagem periodontal está altamente relacionada com a taxa de sobrevivência. O caso apresentado foi capaz de resolver e aliviar os sintomas rapidamente. Um maior tempo de controlo e estudos longitudinais prospetivos são necessários para compreender melhor o prognóstico desta opção de tratamento com estabilização da linha de fissura com uma banda ortodôntica.

http://doi.org/10.24873/j.rpemd.2020.12.759

\#037 Displasia Óssea Florida - A Importância do Diagnóstico Diferencial em 3 Casos Clínicos

Andreia Hortênsio*, Filipa Neto, Joana Rocha, Jorge Martins, António Ginjeira

Faculdade de Medicina Dentária da Universidade de Lisboa

Introdução: A displasia óssea florida, ou displasia cemento-óssea florida, representa um conjunto de lesões fibro-ósseas não-neoplásicas, idiopáticas, localizadas nas áreas de suporte dos dentes ou no processo alveolar edêntulo dos maxilares. É uma condição assintomática, mais frequentemente observada na mandíbula, com maior incidência em mulheres afroamericanas ou asiáticas de meia-idade. O seu diagnóstico é baseado em achados clínicos e radiográficos, incluindo a realização de testes de sensibilidade pulpar, e raramente é necessário tratamento. O objetivo deste trabalho é reportar 3 casos de displasia óssea florida em que o conhecimento da patologia e meios de 
diagnóstico foram fundamentais para a realização de um correto diagnóstico. Descrição dos casos clínicos: Três pacientes do sexo feminino, após consultas e radiografias de rotina, foram encaminhadas para a consulta de Endodontia devido à presença de múltiplas lesões radiolúcidas associadas a peças dentárias, em diversas localizações da mandíbula. A ortopantomografia foi o exame complementar de diagnóstico que permitiu identificar a existência destes múltiplos focos. Na consulta de Endodontia foram realizados testes de sensibilidade ao frio, tendo-se obtido respostas positivas coincidentes com um diagnóstico pulpar de polpa normal nos dentes com lesões associadas. O diagnóstico diferencial passou pelo estabelecimento de lesões de origem não endodôntica. Tendo em conta o aspeto radiográfico característico das lesões, natureza bilateral, bom diagnóstico pulpar dos dentes aparentemente associados e características demográficas das pacientes envolvidas, foi realizado um diagnóstico final de displasia óssea florida. Apenas a monotorização foi recomendada. Discussão e conclusões: A importância dos testes de sensibilidade pulpar para o correto diagnóstico diferencial deste tipo de lesões é fundamental de modo a evitar tratamentos desnecessários. Esta patologia pode apresentar diversas lesões radiolúcidas na fase inicial de progressão devido à substituição de tecido ósseo por tecido fibroso, mimetizando radiograficamente lesões periapicais de origem endodôntica. Posteriormente as lesões radiolúcidas poderão ser substituídas por imagens radiopacas devido à deposição de material mineralizado (osso e cemento). Por vezes as lesões podem infetar e criar problemas de difícil tratamento. Um conhecimento das características da lesão e um correto diagnóstico são fundamentais para definir o plano de ações a tomar.

http://doi.org/10.24873/j.rpemd.2020.12.760

\#038 Iatrogenia em Endodôncia: um caso clínico de acidente com hipoclorito com necrose gengival

Filipa Veiga*, Marcelo Prates, Paula Maria Leite, José Bastos Ferrão, Luís Sanches Fonseca, Ana Teresa Tavares

Centro Hospitalar e Universitário Lisboa Central

Introdução: O Hipoclorito de Sódio ( $\mathrm{NaOCl}$ ) é a solução irrigante mais utilizada no tratamento endodôntico, devido à sua eficácia antimicrobiana, à capacidade de dissolução e remoção de tecido, preço económico e acessibilidade. No entanto, é uma base forte, extremamente corrosiva e de elevada toxicidade. Em contacto com os tecidos periapicais, mucosa oral, ocular e pele, provoca hemólise, ulceração e necrose, pelo que requer a adoção de medidas preventivas durante a sua utilização. O objetivo deste trabalho é relatar um caso de acidente de hipoclorito pela potencial gravidade que esta iatrogenia pode ter em endodôncia, mas também porque a sua incidência correta é subestimada, pelo défice de relatos de caso. Descrição do caso clínico: Homem de 29 anos, saudável, recorre à urgência por edema da face após irrigação canalar com NaOCl durante tratamento endodôntico. O doente referiu ardor súbito durante o tratamento na face e lábio superior e edema que foi agravando progressi- vamente até recorrer à urgência. À observação, apresentava exuberante edema do lábio superior e hemiface esquerda com apagamento do sulco nasogeniano e dor ligeira à palpação. No dente 21 observou-se uma restauração provisória, compatível com o acesso cavitário. Medicou-se com antibiótico e anti-inflamatório esteroide e não esteroide, analgesia e recomendou-se aplicação de gelo local nas primeiras 24 horas e, posteriormente, calor local e bochechos com água morna. Após 5 dias de tratamento, houve redução franca do edema facial, no entanto, apresentava uma complicação incomum, necrose da margem gengival de 21 , pelo que se referenciou a consulta de Periodontologia e terminou o tratamento endodôntico. Discussão e conclusões: Grande parte da iatrogenia por $\mathrm{NaOCl}$ ocorre por extrusão forçada nos tecidos perirradiculares. A adoção de medidas de segurança, aliadas a uma correta técnica de irrigação são fundamentais para a prevenção de acidentes associados à sua utilização. O reconhecimento precoce dos sinais e sintomas associados ao acidente com $\mathrm{NaOCl}$ é fundamental para o prognóstico e evolução do quadro clínico, uma vez que a adoção de medidas imediatas pode diminuir o impacto desta substância nos tecidos. Os acidentes com $\mathrm{NaOCl}$ podem ter consequências graves, nomeadamente edema com compromisso da via aérea e infeção dos tecidos moles necrosados, pelo que os principais objetivos do tratamento passam pela eliminação rápida do irrigante dos tecidos, prevenção da infeção secundária e edema e controlo sintomático.

http://doi.org/10.24873/j.rpemd.2020.12.761

\section{\#039 Úlceras do palato - a propósito de um caso clínico}

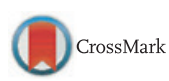

Paula Maria Leite*, Filipa Veiga, José Bastos Ferrão, Ana Teresa Tavares, Marcelo Prates, Patrícia Caixeirinho

Centro Hospitalar e Universitário Lisboa Central

Introdução: As úlceras orais são lesões com elevada prevalência na mucosa oral e cuja apresentação clínica é muitas vezes similar. Contudo, possuem uma etiologia muito variada, podendo resultar de traumatismos, iatrogenia, ou ser manifestações orais de patologias sistémicas como infeções virais ou bacterianas, doenças mucocutâneas ou mesmo doenças neoplásicas. Apresenta-se um caso clínico de lesões ulcerativas no palato, pondo em evidência a importância de realizar um estudo detalhado das mesmas de forma a excluir doença grave, nomeadamente maligna. Descrição do caso clínico: Homem de 43 anos, com antecedentes de doença arterial periférica, importantes hábitos tabágicos e etanólicos e comportamentos sexuais de risco, recorre à urgência por lesões ulcerativas no palato. As lesões são dolorosas, de crescimento progressivo e com um mês de evolução. Há história de extração dentária recente na área de uma das lesões. Ao exame objetivo, o doente apresentava doença periodontal avançada e duas lesões ulceradas com exposição óssea: uma desde o rebordo alveolar da região pré-molar do primeiro quadrante até à linha média do palato e outra na região pré-molar do segundo quadrante. Eram palpáveis adenomegalias cervicais bilaterais. Foi feito 